\title{
Coronary artery fistulas morphology in coronary computed tomography angiography
}

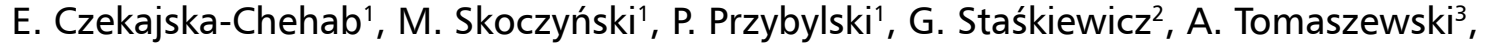 \\ E. Siek ${ }^{1}$, J. Kurzepa ${ }^{1}$, M. Skoczyński ${ }^{4}$, A. Drop ${ }^{1}$ \\ ${ }^{1} 1^{\text {st }}$ Department of Radiology, Medical University of Lublin, Poland \\ ${ }^{2}$ Department of Human Anatomy, Medical University of Lublin, Poland \\ ${ }^{3}$ Department of Cardiology, Medical University of Lublin, Poland \\ ${ }^{4}$ Department of Obstetrics and Gynaecology, Medical University of Lublin, Poland
}

[Received: 13 September 2019; Accepted: 22 October 2019]

Background: The aim of the study was to evaluate coronary artery fistulas (CAFs) in coronary computed tomography angiography (coronary CTA) and verify whether there is correlation between the fistula's morphology and other cardiac functional findings and clinical data.

Materials and methods: A group of 14,308 patients who were diagnosed in coronary CTA was retrospectively analysed. Achieved data were related to referrals. Results: Coronary artery fistula frequency was $0.43 \%$ in the examined population. The assessment of coronary artery disease was the most frequent indication for the examination. In 2 out of 3 cases the diagnosis of CAFs was incidental. Fistulas to cardiac chambers were significantly shorter than those to other vascular structures (19.9 vs. $61.8 \mathrm{~mm}$, respectively, $p=0.001$ ). Pulmonary trunk was most often the drainage site. Fistulas with singular supply and drainage constituted the majority. The new morphologic classification of CAFs was introduced with linear, spiral, aneurysmal, grid-like and mixed types. Most numerous was the spiral type group. Patients with aneurysmal fistulas had a tendency for wider diameter of aorta and pulmonary trunk. Smallest left ventricle fraction was observed in gridlike fistulas (48.0\%, comparing to 59.2\% for all patients with fistulas, $p=0.001$ ). Concomitant abnormalities were found in $13.1 \%$ of CAFs patients.

Conclusions: Computed tomography angiography has proven to be a useful tool in CAFs detection and morphological assessment. Proposed classification may simplify the predictions whether fistula has a significant influence on cardiac function; however, further studies are needed. (Folia Morphol 2020; 79, 4: 777-785)

Key words: coronary, fistula, coronary computed tomography angiography, angiography, classification

\section{INTRODUCTION}

Coronary artery fistulas (CAFs) are additional, abnormal pathways of communication between a coronary artery and other vascular structures (coronary arteriovenous fistulas [CAVFs]) or cardiac chambers (coronary cameral fistulas [CCFs]) [8, 22]. First described by Krause in 1865 [9] CAFs were found throughout the years by means of coronary angiography, and recently in coronary computed tomography angiographies (coronary CTAs), magnetic resonance angiographies (MRAs) and exceptionally cardiac echocardiography. 
The frequency of CAFs varies excessively. Lowest frequency, reaching $0.002 \%$ was reported in the general population [14], whereas in patients undergoing invasive coronarography varies within the range $0.05-0.9 \%[11,14,17,26,28,29]$. General occurrence is only insignificantly altered by sporadic acquired CAFs as a result of cardiac surgery or trauma $[6,16]$.

Symptomatic CAFs in adults constituted about $40 \%$ of all [3]. Detection of this abnormality may be crucial in symptomatic patients to provide successful treatment [24]. Symptoms were reported to occur especially in large left-to-right shunting fistulas [3]. The vessels leading the blood flow to right ventricle and right atrium can possibly be the reason of local micro-ischaemia. Individuals presenting these symptoms may experience continuous heart murmur, dyspnoea, chest pain, right-ventricular dysfunction-related conditions in cases of large fistulas. Haemoptysis may appear in coronary-to-bronchial artery fistulas [18]. Sudden cardiac death being one of the manifestations highlights the importance of diagnosis [20]. Complications such as endocarditis, arrhythmia, myocardial ischaemia, pulmonary hypertension, congestive heart failure and local fistula conditions such as rupture or thrombosis may occur.

High percentage of CAF detection, the possibility of complex evaluation of the vessels together with the concomitant heart abnormalities and lower radiation doses in modern computed tomography (CT) scanners provide the $\mathrm{CT}$ with the chance to displace coronary angiography as the gold standard for CAFs diagnosis. The aim of the study is to give detailed features of CAFs in coronary CTA and relate those findings to cardiac function, clinical and previously acquired data by means of angiography and former CT-based studies.

\section{MATERIALS AND METHODS}

A total group of consecutive 14,308 patients (males: 6821, females: 7487, mean age: $58.2 \pm$ \pm 14.8 years; age range: $1-93$ ) who underwent electrocardiogram (ECG)-gated multidetector CT (MDCT) examination in First Department of Radiology, Medical University of Lublin between January 2006 and January 2018, was retrospectively reviewed for CAF. In over $70.0 \%$ of cases coronary artery disease (CAD) or control after invasive treatment were the main indications for coronary CTA.

Computed tomography protocol. CT data were acquired with retrospective ECG-gated cardiac CT scans by MDCT in 9727 cases by 64-row scanner (LightSpeed VCT, General Electric Healthcare, Milwaukee Wisconsin, USA) and both retrospectively or prospectively in 4581 cases by 256-row scanner (Revolution, General Electric Healthcare, Milwaukee Wisconsin, USA). The scan parameters were set as following: for 64 row scanner - collimation $64 \times 0.6 \mathrm{~mm}$ with a z-flying focal spot, pitch $0.16: 1-0.25: 1$; gantry rotation time $0.35 \mathrm{~s}$; for 256 row scanner - tube voltage of $120 \mathrm{kV}$; collimation $256 \times 0.625 \mathrm{~mm}$ with a cardiac axial spot, gantry rotation time $0.28 \mathrm{~s}$. In all examinations ECG-dependent tube current modulation was used. If a patient's heart rate exceeded 65 beats/min, the heart rate was controlled with the oral $\beta 1$-receptor blocker metoprolol.

For coronary CTA, each patient was given an injection of $70-140 \mathrm{~mL}$ of iodine contrast agent (Ultravist 370, $370 \mathrm{mg} \mathrm{l} / \mathrm{mL}$, Bayer Schering Pharma; or lomeron $400,400 \mathrm{mg} \mathrm{l} / \mathrm{mL}$, Bracco) depending on weight, at a flow rate of $4-5.5 \mathrm{~mL} / \mathrm{s}$ followed by a $50-\mathrm{mL}$ injection of saline solution. Injection was performed through an antecubital vein. Administration of the contrast material was controlled by bolus tracking in the ascending aorta. The scan delay was chosen manually in SmartPrep technique or test bolus technique. The scan direction was craniocaudal and the range from the level of the tracheal bifurcation to the level of the inferior margin of the heart for routine coronary CTA and from the level of the clavicle to the level of inferior margin of the heart for patients who had undergone coronary artery bypass grafts. The images were reconstructed in 10 series with 10\% R-R interval (5-95\%).

Image reconstruction. All the imaging data were transferred to dedicated workstation (Advantage Workstation version 4.3, 4.6 or 4.7, General Electric Healthcare, Milwaukee Wisconsin USA), post-processed and carefully reviewed. The data from 14,308 consecutive patients were assessed by 2 cardiac radiologists. Apart from that further analysis of 61 patients with fistulas was performed, by 3 experienced radiologists (with 16, 10 and 2 years of experience in CT cardiac imaging).

The CAFs were evaluated with the original transverse images (Fig. 1A, B), multiplanar reconstructions (MPR), maximum intensity projections (MIP, Fig. 1C), volume-rendered images, as well as curve reconstructions (CMPR, Fig. 1D).

The CAFs characteristics included the vessels of origin, the drainage vessels, the presence of aneurysms (defined as dilatation 1.5 times the diameter of 

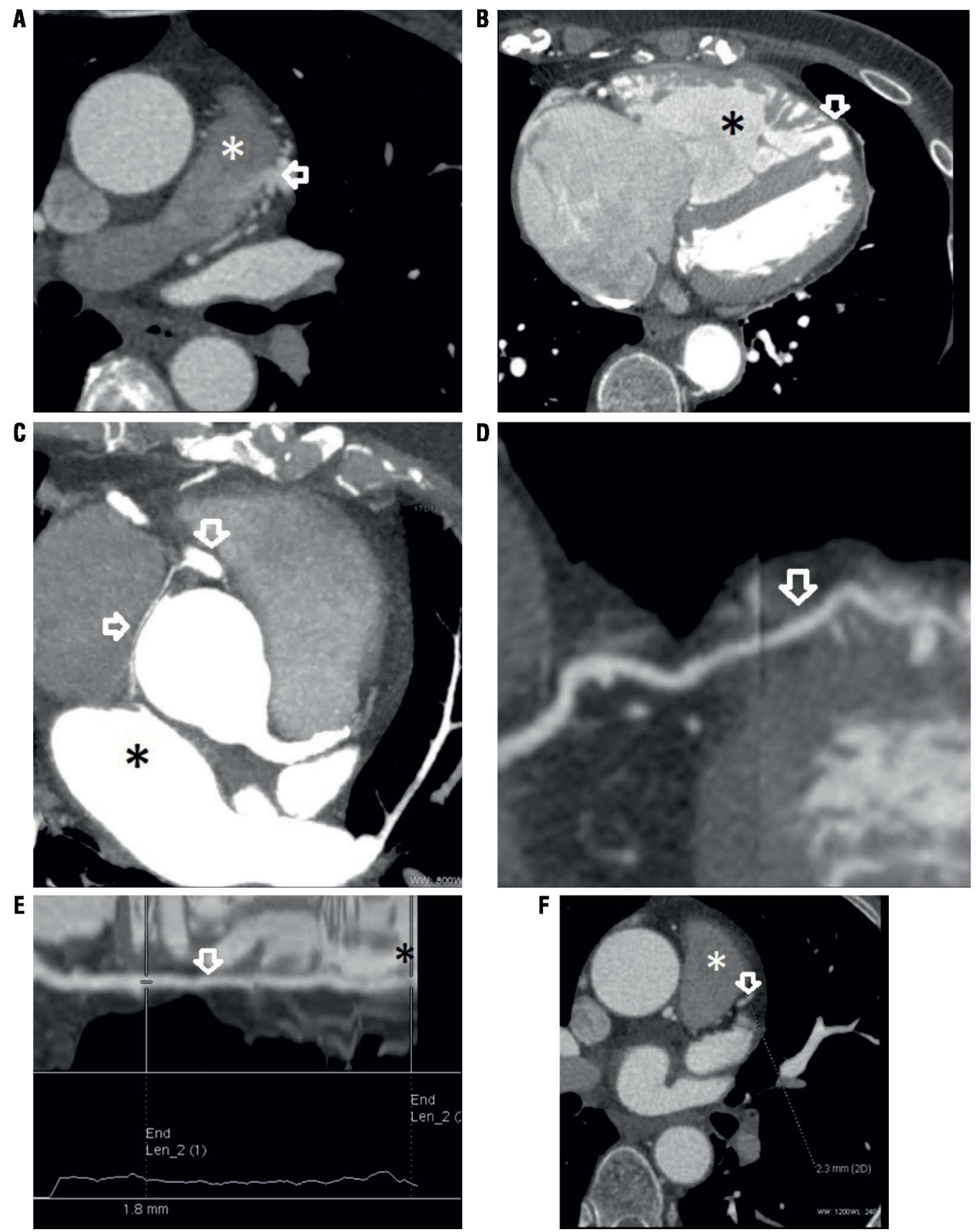

Figure 1. Methods of fistulas evaluation; A. A mixed type fistula with aneurysmal widening and visible contrast jet to the pulmonary trunk (*pulmonary trunk; $\leftarrow$ a mixed type fistula); B. A visible contrast intensity in the right ventricle tip, consistent with left coronary artery (LCA) fistula to right ventricle ( ${ }^{*}$ right ventricle; $\downarrow$ contrast extravasation from the LCA fistula); C. A linear type fistula originating from the right coronary artery (RCA) in maximum intensity projection (* left atrium; $\downarrow R C A ; \rightarrow R C A$ fistula); D. Example of LCA fistula to right ventricle in curve reconstruction ( ${ }^{*}$ right ventricle; $\downarrow$ LCA fistula); E. Example of fistula's shortest distance of connection measurement in longitudinal reconstruction ( ${ }^{*}$ right ventricle; $\downarrow$ LCA fistula); F. Example of diameter measurement in a left coronary artery fistula (*pulmonary trunk; $\downarrow$ fistula vessel).

vessels), combined congenital or acquired anomalies, and the relations with the adjacent structures.

Following morphological parameters of CAF were measured: shortest distance of connection (SDC) along the vessel in longitudinal reconstructions between the origin of the fistula and the drain location
(Fig. 1E), fistula range (FR) basing on oblique and curved reconstructions, with supplementary use of three-dimensional reconstructions to give the largest extent of a fistula in one dimension, for fistulas consisting of one main vessel additionally diameter and at the site of origin, diameter and area at the site of 

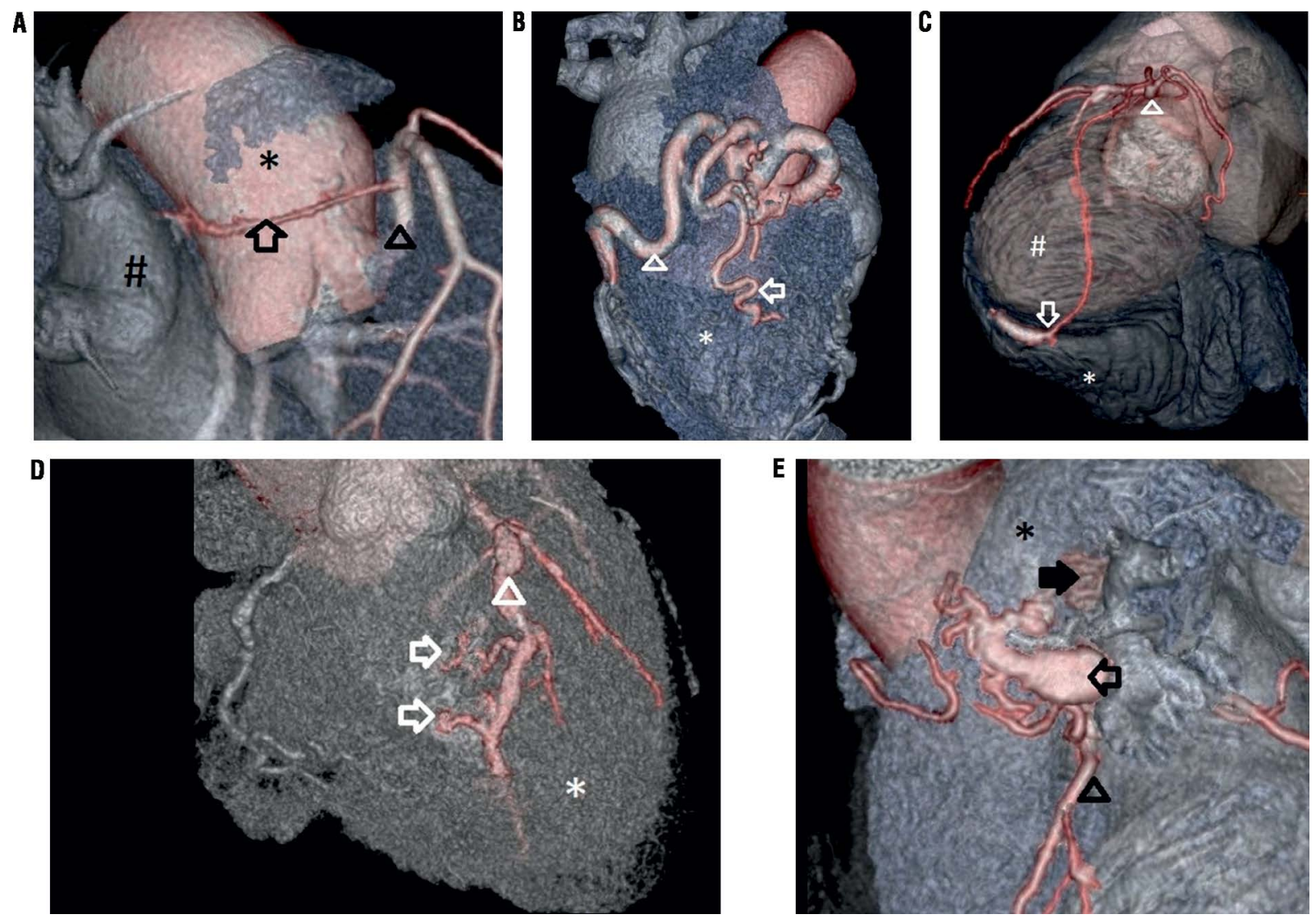

Figure 2. Coronary artery fistula types; A. Linear type fistula ( $\uparrow$ ); right coronary artery (RCA) ( $\Delta$ supply); left atrium (\# drainage); ascending aorta $\left({ }^{*}\right)$; B. Spiral type fistula $(\leftarrow)$; RCA supply $(\Delta)$; right ventricle $\left({ }^{*}\right.$ drainage); C. Aneurysmal type fistula $(\downarrow)$; left coronary artery (LCA) ( $\Delta$ supply); right ventricle (* drainage); left ventricle (\#); D. Grid-like type fistula $(\rightarrow) ;$ LCA ( $\Delta$ supply); left ventricle $\left({ }^{*}\right.$ drainage); E. Mixed type fistula. Aneurysmal part of the fistula $(\leftarrow)$; spiral part of the fistula $(\rightarrow)$; LCA ( $\Delta$ supply); pulmonary trunk ${ }^{*}$ drainage).

termination, diameter and area at the narrowest point of CAF (Fig. 1F). Diameters of ascending aorta and pulmonary trunk, ejection fraction of right and left ventricles were also calculated. Furthermore, coronary arteries were evaluated for CAD.

Single supply single drain fistulas were classified as simple fistulas, in contrast to multiple fistulas with more than one supplying vessel or more than one drainage site.

For the aim of classifying fistulas to large and small ones a threshold of $1.5 \mathrm{~mm}$ of minimal diameter in simple fistulas and $1.5 \mathrm{~mm}$ of minimal diameter of the broadest collateral in multiple fistulas was set to distinguish large from small fistulas. The diameter was chosen based on former studies, which predicted haemodynamically significant flow and negligible CT artefacts role during the assessment [25].

Based on CAF images in coronary CTA an attempt of classifying fistulas was made. Fistulas leading directly to cardiac chamber or vessel were assigned to linear type (Fig. 2A). Those having at least one 180 degree turn throughout their run were the spiral type (Fig. 2B). When at least one local dilatation larger than $150 \%$ of the regular fistula diameter was observed fistula was classified as aneurysmal type (Fig. 2C). Gridlike type fistulas were characterised by multiple supplying vessels and/or multiple drainage sites (Fig. 2D). When a fistula was combining at least 2 features of spiral, aneurysmal and grid-like types was assigned to mixed type (Fig. 2E).

\section{Statistical analysis}

Statistical analysis was performed with SPSS 16.0, SPSS Inc, Chicago, IL. $\chi^{2}$ test was used to compare qualitative data, and the Mann-Whitney test for quantitative data. Correlation of linear measurements has been assessed with Pearson coefficient. Values of $p \leq 0.05$ were considered to be significant.

\section{Disclousures}

This study have been performed in accordance with the ethical standards as laid down in the 1964 
Table 1. Average shortest distances of coronary cameral fistula (CCF) connection depending on drainage site

\begin{tabular}{|c|c|c|c|c|c|c|c|c|c|}
\hline \multirow{3}{*}{$\begin{array}{l}\text { Drainage } \\
\text { site }\end{array}$} & \multicolumn{9}{|c|}{ Coronary artery fistula type } \\
\hline & \multicolumn{4}{|c|}{ CCF } & \multicolumn{5}{|c|}{ CAVF } \\
\hline & $\begin{array}{c}\text { RA } \\
(n=4)\end{array}$ & $\begin{array}{c}\text { RV } \\
(n=8)\end{array}$ & $\begin{array}{c}\text { LA } \\
(n=7)\end{array}$ & $\begin{array}{c}L V \\
(n=2)\end{array}$ & $\begin{array}{c}\text { PT } \\
(n=34)\end{array}$ & $\begin{array}{c}\text { BA } \\
(n=8)\end{array}$ & $\begin{array}{c}\text { Other CA } \\
(\mathrm{n}=1)\end{array}$ & $\begin{array}{l}\text { Heart vein } \\
(\mathbf{n}=3)\end{array}$ & $\begin{array}{c}\text { Aorta } \\
(n=1)\end{array}$ \\
\hline $\mathrm{SDC}[\mathrm{mm}]$ & 24.0 & 19.3 & 17.1 & 22.5 & 49.3 & 75.6 & 119.0 & 163.7 & 14.0 \\
\hline Range [mm] & $14.0-42.0$ & $1.0-57.0$ & $0.9-62.0$ & $22.0-23.0$ & $7.0-120.0$ & $27.0-170.0$ & - & $14.0-257.0$ & - \\
\hline
\end{tabular}

CAVF — coronary arteriovenous fistula; RA — right atrium; RV — right ventricle; LA — left atrium; LV — left ventricle; $\mathrm{PT}$ — pulmonary trunk; BA — bronchial artery; CA — coronary artery; SDC — shortest distance of connection

Declaration of Helsinki and its later amendments and was approved by the local ethical committee of Medical University of Lublin (reference number KE-0254/186/2015).

Informed consent was obtained from all individual participants included in the study.

\section{RESULTS}

Coronary artery fistulas were found in 61 (0.43\%) of all 14,308 coronary CTAs performed in our department between 01.01.2006 and 31.01.2018. All of them were classified as congenital. Mean age in the group of patients with CAF was $58.2 \pm 16.5$, age range 18-81 (33 females; $54.1 \%$ ). CAD suspicion was the most frequent clinical indication to coronary CTA ( $n=24 ; 39.3 \%$ ), followed by previous CAF diagnosis or suspicion ( $n=21 ; 34.4 \%$ ) and other vascular pathologies other than fistulas ( $n=10 ; 16.4 \%)$. Least numerous groups referred to coronary CTA consisted of patients before pulmonary veins ablation and arrhythmia of unknown origin (both 3; 4.9\%).

There were 44 simple fistulas and 17 multiple ones. There were 10 fistulas classified as large.

In the examined group there were 68 drainage sites. Not only coronary cameral fistulas were less numerous than coronary arteriovenous fistulas (21; $30.9 \%$ vs. $47 ; 69.1 \%$ ), but also were statistically significantly shorter (average SDC $19.9 \mathrm{~mm}$; range 1.0-62.0 mm, standard deviation [SD] $16.7 \mathrm{~mm}$ vs. $61.8 \mathrm{~mm}$; range $7.0-256.8 \mathrm{~mm}$, SD $52.5 \mathrm{~mm}$; $p=0.001$; Table 1). Fistula to pulmonary trunk $(n=34)$ represented $55.7 \%$ of all fistulas, and was most often found CAF. Most often found coronary cameral fistula was leading to right ventricle $(n=8,13.1 \%$ of all fistulas).

In the group there were 78 supplying vessels. Right coronary artery (RCA) was the supply for fistulas leading to left atrium ( $n=7)$, pulmonary trunk $(n=4)$, right atrium ( $n=3)$, right ventricle $(n=2)$, and singular fistula to heart vein. Left coronary artery
Table 2. Number of fistulas originating from the right coronary artery (RCA) and left coronary artery (LCA) leading to various locations

\begin{tabular}{|c|c|c|}
\hline & RCA & LCA \\
\hline PT & 4 & 24 \\
\hline Left atrium & 7 & 0 \\
\hline Right ventricle & 2 & 6 \\
\hline Bronchial arteries & 0 & 7 \\
\hline Right atrium & 3 & 0 \\
\hline Heart vein & 1 & 2 \\
\hline Aorta & 0 & 1 \\
\hline Left ventricle & 0 & 1 \\
\hline LAD-RCA (combined) & \multicolumn{2}{|c|}{$1(2)$} \\
\hline PT (combined) & \multicolumn{2}{|c|}{$6(12)$} \\
\hline Right atrium (combined) & \multicolumn{2}{|c|}{$1(2)$} \\
\hline Left ventricle (combined & \multicolumn{2}{|c|}{$1(2)$} \\
\hline Bronchial arteries (combined) & \multicolumn{2}{|c|}{$1(2)$} \\
\hline Total & \multicolumn{2}{|c|}{78} \\
\hline
\end{tabular}

PT — pulmonary trunk; LAD — left anterior descending branch

(LCA), regarding all branches, supplied fistulas to pulmonary trunk $(n=24)$, bronchial arteries $(n=7)$, right ventricle $(n=6)$, heart veins $(n=2)$ and singular aortic and left ventricle fistulas. In one case LCA had direct connection to RCA.

Both RCA and LCA supplied 6 fistulas to pulmonary trunk and singular fistulas to right atrium, left ventricle and bronchial arteries (Table 2 ).

Fistulas originating from the RCA had the average SDC of $46.2 \mathrm{~mm}$ (range $0.9-257.0 \mathrm{~mm}$; SD $60.8 \mathrm{~mm}$ ), whereas from the LCA of $49.5 \mathrm{~mm}$ (range 1.0$-220.0 \mathrm{~mm}$; SD 44.0). Left circumflex artery gave most of the longest fistulas ( $n=10$ ) with the mean length of $103.4 \mathrm{~mm}$ (range 27.0-220.0 mm; SD $68.6 \mathrm{~mm}$ ), on the contrary it was the left anterior descending branch (LAD) to have the shortest mean distance of connection - $38.4 \mathrm{~mm}$ (range 1.0-119.0 mm; SD $23.8 \mathrm{~mm}$ ). 
Table 3. Fistulas supply and drainage types

\begin{tabular}{cccc}
\hline \multicolumn{4}{c}{ Type of coronary artery fistula } \\
\hline $\begin{array}{c}\text { 1 supply, } \\
\text { 1 drain }\end{array}$ & $\begin{array}{c}\text { 2 supplies, } \\
\text { 1 drain }\end{array}$ & $\begin{array}{c}\text { 1 drain, } \\
\text { 2 supplies }\end{array}$ & $\begin{array}{c}\text { 2 or more } \\
\text { supplies/drains }\end{array}$ \\
\hline $44(71.1 \%)$ & $4(6.6 \%)$ & $6(9.8 \%)$ & $7(11.5 \%)$ \\
\hline
\end{tabular}

The majority of fistulas (71.1\%) resulted to be single supply single drain type (Table 3 ). For this type the mean diameter at origin was $2.2 \mathrm{~mm}$ with the range 0.6-17 mm, SD $3.0 \mathrm{~mm}$, at ending the mean diameter was 2.1 with the range $0.7-5.0 \mathrm{~mm}$, SD $1.8 \mathrm{~mm}$. The mean diameter at its narrowest point was $1.2 \mathrm{~mm}$, range $0.6-5.5 \mathrm{~mm}$, SD $1.2 \mathrm{~mm}$, mean narrowest area was $2.2 \mathrm{~mm}^{2}$, SD $6.5 \mathrm{~mm}$. A strong positive correlation between the diameter at origin and shortest distance of connection was found in the single supply single drain type (correlation coefficient 0.6, $p=0.001$ ). Detailed analysis for multiple fistulas was abandoned due to limited number of examples and negligible haemodynamic role.

Spiral type of fistula occurred most often $(n=18$; $29.5 \%)$, followed by linear type $(n=15 ; 24.6 \%)$. The former type had both mean SDC and FR greater than the latter. Largest mean SDC was observed in the aneurysmal group ( $81.2 \mathrm{~mm}$, SD $48.5 \mathrm{~mm}$ ), whereas it was the mixed type to have the largest mean FR (50.0 mm, SD $19.6 \mathrm{~mm}$ ) due to containing most complicated structure. Detailed data are given in Figure 3.

On average aneurysmal and mixed fistulas combining spiral features with aneurysmal dilatation were wider than linear and spiral, regardless of the location of measurement (Table 4).

Significant coronary artery stenosis was found in 13 individuals out of 61 with CAF ( 6 females, 7 males). Patients with aneurysmal fistulas were less likely to have significant changes in coronary arteries comparing to the whole investigated group $(11.1 \%$ vs. $21.3 \%)$, although this correlation was not statistically significant. Furthermore, aneurysmal group fistulas' mean diameters of ascending aorta and pulmonary trunk slightly exceeded the normal limits (35.2 mm; SD $5.7 \mathrm{~mm}$, and $29.2 \mathrm{~mm}$; SD $5.9 \mathrm{~mm}$, respectively), whereas in other fistula types mean diameters were within the normal values $(33.3 \mathrm{~mm}$; SD $5.3 \mathrm{~mm}$ and $28.1 \mathrm{~mm}$; SD $4.9 \mathrm{~mm}$, respectively for the whole group).

In the examined group mean ejection fraction for the left ventricle was $59.2 \%$ (range $30.7-82.1 \%$, SD 9.8\%), for the right ventricle $45.8 \%$ (range $11.1-$

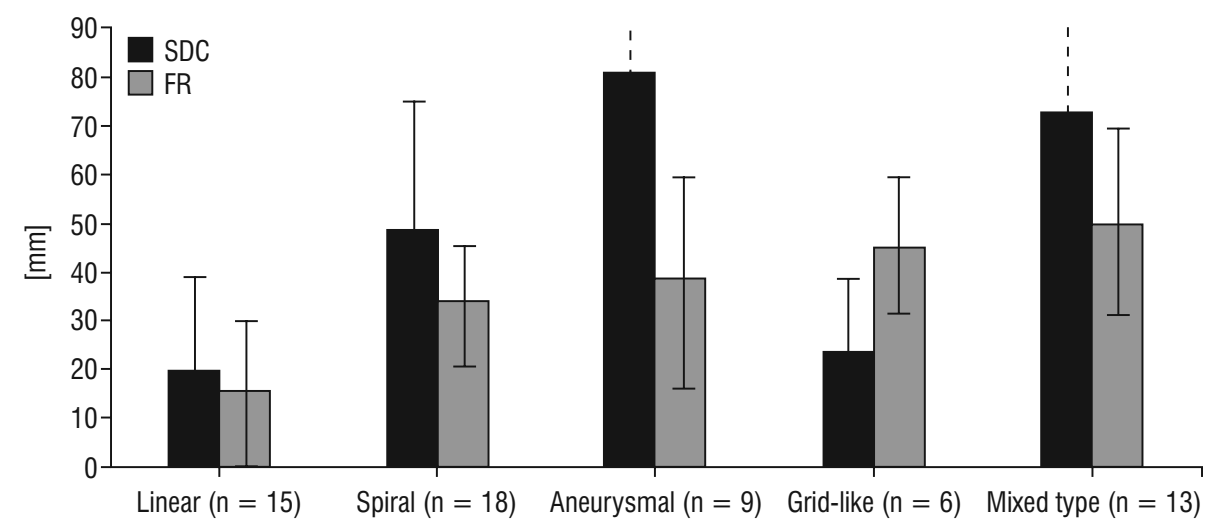

Figure 3. Characteristics of the fistula types; FR — fistula range; SDC — shortest distance of connection.

Table 4. Diameter and area of single supply single drain fistulas $(n=44)$

\begin{tabular}{lcccccc}
\hline $\begin{array}{l}\text { Morphological type } \\
\text { of CAF/measurement }\end{array}$ & $\begin{array}{c}\text { Diameter at the } \\
\text { site of origin } \\
{[\mathrm{mm}]}\end{array}$ & $\begin{array}{c}\text { Diameter at the } \\
\text { site of termination } \\
{[\mathrm{mm}]}\end{array}$ & $\begin{array}{c}\text { Diameter at the } \\
\text { narrowest point } \\
{[\mathrm{mm}]}\end{array}$ & $\begin{array}{c}\text { Area at the } \\
\text { site of origin } \\
{\left[\mathrm{mm}^{2}\right]}\end{array}$ & $\begin{array}{c}\text { Area at the site } \\
\text { of termination } \\
{\left[\mathrm{mm}^{2}\right]}\end{array}$ & $\begin{array}{c}\text { Area at the } \\
\text { narrowest point } \\
{\left[\mathrm{mm}^{2}\right]}\end{array}$ \\
\hline Linear, $\mathrm{N}=15$ (range) & $1.3(0.8-2.3)$ & $1.4(0.8-2.4)$ & $1(0.6-2.1)$ & $1.4(0.5-4.2)$ & $1.8(0.5-4.5)$ & $0.9(0.3-3.5)$ \\
Spiral; $\mathrm{N}=18$ (range) & $1.7(1.1-2.3)$ & $1.9(0.7-4.5)$ & $1(0.4-1.6)$ & $2.3(0.9-4.2)$ & $3.6(0.4-15.9)$ & $0.8(0.1-2.0)$ \\
Aneurysmal; $\mathrm{N}=9$ (range) & $3.5(0.4-17.0)$ & $2.4(0.8-5.5)$ & $1.4(0.4-5.0)$ & $27.9(0.1-226.9)$ & $6.8(0.5-23.7)$ & $2.9(0.1-19.6)$ \\
Mixed; $\mathrm{N}=2$ (range) & $7.8(2.3-13.3)$ & $6.7(2.5-11.0)$ & $4.1(1.1-7.0)$ & $71.6(4.2-138.9)$ & $50.0(4.9-95.0)$ & $19.7(0.9-38.5)$ \\
\hline
\end{tabular}

CAF — coronary artery fistula 
$-66.2 \%$, SD $10.8 \%)$. Ejection fractions for both ventricles were the smallest in grid-like type fistulas, with mean value of $48.0 \%$, SD $11.9 \%$ for the left ventricle, whereas in other types than grid-like type types amounted to $60.4 \%$, SD $9.8 \%$.

The correlation for differences in ejection fraction in grid-like type fistulas comparing to the entire population with fistulas has proven to be statistically significant $(p=0.001)$. Individuals with grid-like fistulas were referred for the coronary CTA with CAF suspicion or other vascular pathologies; none of them was referred for isolated further diagnosis of CAD. Patients with grid-like fistulas were the youngest with mean age 51.2. Five in 6 patients with the grid-like type had a large fistula. All of the patients in grid-like type fistula were having left-to-right shunting, whereas in the whole group it was $80.3 \%$ (49 of 61 patients).

Concomitant abnormalities were: ventricular septal defect (VSD) $(n=3)$, other coronary anomalies $(n=3)$, bicuspid aortic valve $(n=3)$, atrial septal defect (ASD) $(n=2)$, partial absence of pericardium $(n=1)$. Those 12 abnormalities were observed in 8 patients. In 53 (87\%) patients RCA was the dominant artery.

\section{DISCUSSION}

In the examined population the prevalence of CAF was $0.43 \%$, whereas in previous coronary CTA researches it amounted to $0.2-0.9 \%[11,28,29]$, similarly to angiography reports $-0.3-0.9 \%$ [26]. The majority of detected fistulas reported in previous reports were described as congenital [6, 21]; our study proved this findings - no fistula in our group was classified as acquired. Out of the 61 patients CAF was previously diagnosed or suspected in 21 (34\%) cases. The accessible literature lacks comparable data.

Pulmonary trunk was most often the drainage site $(55.7 \%)$, similarly to previous reports $[1,29]$, so was the LAD the supplying vessel (54.1\%). A large, recent, coronarography study, which included 298,558 patients with 261 noted fistulas in Polish population, gives alike most often found drainage site and supplying vessel [15].

Including multiple fistulas, CCFs accounted for $69.1 \%$ of all CAF cases. Even though fistulas originating from the LAD branch were the shortest $(38.4 \mathrm{~mm})$, this fact does not determine they also provided the highest blood flow, as shortest fistulas had also the smallest diameter.

Since most CAFs are reported to be congenital they were included in the Ogden classification [13] of congenital variations of the coronary artery and assigned to the group of major coronary anomalies. Angelini [2] and Dodge-Khatami's classification [7], and Angelini [2] and Dodge-Khatami's modified classifications [7] are currently used for coronary anatomy anomalies, both extracting CAFs $[2,7]$. The Sakakibara et al. [19] classification, which is based on angiography, divides fistulas depending on dilatation of supplying vessel. The mentioned and accessible classifications do not divide the fistulas based on their clinical or functional relevance. Taking the advantage of $\mathrm{CT}$, which enables the morphological assessment of a fistula and potential additional findings, a novel system of classifying the fistulas was proposed by the authors, with five types: linear, spiral, aneurysmal, grid-like and mixed. The presented morphological classification may be used by radiologists to assess all CAFs, regardless of the supplying vessel, fistula diameters and the drainage site, being a useful tool for qualification to intravascular or surgical corrections.

Linear type fistulas were the shortest with the shortest fistula range. Spiral type fistulas, found most often (29.5\%), were longer than linear due to their course. Possibly relevant findings were observed in the aneurysmal type fistulas. Firstly, patients with aneurysmal fistulas had wider ascending aorta and pulmonary trunk in comparison to other fistula types. This may correspond to congenital tendency in cases of multiple aneurysms in other locations. Secondly, fewer cases with relevant CAD were found in the aneurysmal group.

Individuals with grid-like type were among the youngest and with the lowest left ventricle fraction. In the grid-like type fistulas there were 5 patients with large fistula (83\%), comparing to the general occurrence of $8 \%$. This difference has proven to be statistically significant. All of the grid-like fistulas were left-to-right shunting. Mentioned features, combined with the fact that neither of them was referred for the coronary CTA due to CAD, suggests these patients had haemodynamically significant fistulas. Potentially clinically relevant findings in aneurysmal and grid-like fistula types need further researches due to limited number of patients in mentioned groups.

Fistulas attached to aneurysmal and mixed types were connected with aneurysms, in 18 out of 61 individuals (29.5\%), which confirms the previously reported tendency of aneurysmal occurrence in fistulas [19]. No typical concomitant anomalies were bound with the new fistula types. No statistically significant 
relationship was observed between coronary artery domination and type of the fistula.

The proposed classification due to correlation with clinical findings can possibly be helpful in improving the communication between radiologists and clinicians. Blood flow through the CAF may be of a significant importance especially in patients with severe CAD in which distal to the stenosis perfusion may be furtherly reduced due to the leakage through the fistula.

Eight (13\%) patients had concomitant heart abnormalities. VSD were most often observed, as well as other coronary anomalies and bicuspid aortic valve. According to the previous reports CAFs occur with concomitant congenital pathologies in 20-45\% [12]. Tetralogy of Fallot, VSD aneurysm of the sinuses of Valsalva, anomalous origin of the LAD, ASD patent ductus arteriosus, tricuspid and pulmonary valve disorders were observed in previous studies $[4,5]$. The difference of concomitant abnormalities occurrence may be due to the fact that all of examined patients were adults.

Pre-operative planning based on CT multiplanar and three-dimensional reconstructions gives surgeons the chance to localise all sections of complex configurations, being probably more clinically relevant than short and mostly narrow linear fistulas. Adequate clinical indications need to be fulfilled for the examination as it uses ionizing radiation and possible iodinated contrast side effects. In previous studies coronary CTA has proven to be a compelling diagnostic tool before surgery $[10,23]$ and probably it may reduce the chance of misdiagnosis, which was reported in the case of echocardiography imaging [27].

\section{Limitations of the study}

The limitations of the research arise mostly from the methodology and the pursuit of least invasive diagnostic attitude. In terms of asymptomatic fistulas, which were observed most often, further coronarography or surgery would not be justified only to verify the CTA findings. What is more, small number of cases in the aneurysmal type and grid-like type fistulas may demand further analysis in a larger group to verify potentially important findings, such as lowered left ventricle ejection fraction in the grid-like type fistulas.

\section{CONCLUSIONS}

Coronary CTA gave a detailed spatial image of coronary fistulas and enabled the evaluation of CAD and cardiac function being a reliable non-invasive diagnostic tool.

Coronary artery fistulas are rare, often asymptomatic findings. Coronary CTA is a useful tool for CAF detection and morphological characterisation. New morphological classification may be a helpful tool in anticipating CAF influence on the cardiac function.

\section{REFERENCES}

1. Albeyoglu S, Aldag M, Ciloglu U, et al. Coronary arteriovenous fistulas in adult patients: surgical management and outcomes. Braz J Cardiovasc Surg. 2017; 32(1): 15-21, doi: 10.21470/1678-9741-2017-0005, indexed in Pubmed: 28423125.

2. Angelini P. Normal and anomalous coronary arteries: definitions and classification. Am Heart J. 1989; 117(2): 418-434, doi: 10.1016/0002-8703(89)90789-8, indexed in Pubmed: 2644796.

3. Buccheri D, Chirco PR, Geraci S, et al. Coronary artery fistulae: anatomy, diagnosis and management strategies. Heart Lung Circ. 2018; 27(8): 940-951, doi: 10.1016/j. hlc.2017.07.014, indexed in Pubmed: 29503240.

4. Carrel T, Tkebuchava T, Jenni R, et al. Congenital coronary fistulas in children and adults: diagnosis, surgical technique and results. Cardiology. 1996; 87(4): 325-330, doi: 10.1159/000177114, indexed in Pubmed: 8793168.

5. Cebi N, Schulze-Waltrup N, Frömke J, et al. Congenital coronary artery fistulas in adults: concomitant pathologies and treatment. Int J Cardiovasc Imaging. 2008; 24(4): 349-355, doi: 10.1007/s10554-007-9277-x, indexed in Pubmed: 17965946.

6. Chiu SN, Wu MH, Lin MT, et al. Acquired coronary artery fistula after open heart surgery for congenital heart disease. Int J Cardiol. 2005; 103(2): 187-192, doi: 10.1016/j. ijcard.2004.09.005, indexed in Pubmed: 16080979.

7. Dodge-Khatami A, Mavroudis C, Backer CL. Congenital heart surgery nomenclature and database project: anomalies of the coronary arteries. Ann Thorac Surg. 2000; 69(4 Suppl): S270-S297, doi: 10.1016/s0003-4975(99)01248-5, indexed in Pubmed: 10798435.

8. Gautam R, James ED, David RH, et al. Coronary artery fistulae. Circulation: Cardiovasc Interv. 2015; 8(11), doi: 10.1161/circinterventions.115.003062.

9. Krause W. Uber den ursprung einer accessorischen a. coronaria aus der a. pulmonalis. Z Ratl Med. 1865; 24: 225-227.

10. Li A, Peng Z, Zhang C. Comparison of echocardiography and 64-multislice spiral computed tomography for the diagnosis of pediatric congenital heart disease. Med Sci Monit. 2017; 23: 2258-2266, doi: 10.12659/msm.901546, indexed in Pubmed: 28500278.

11. Lim JJ, Jung JIm, Lee BY, et al. Prevalence and types of coronary artery fistulas detected with coronary $C T$ angiography. AJR Am J Roentgenol. 2014; 203(3): W237-W243, doi: 10.2214/AJR.13.11613, indexed in Pubmed: 25148179.

12. Mangukia CV. Coronary artery fistula. Ann Thorac Surg. 2012; 93(6): 2084-2092, doi: 10.1016/j. athoracsur.2012.01.114, indexed in Pubmed: 22560322. 
13. Ogden J. Congenital anomalies of the coronary arteries. Am J Cardiol. 1970; 25(4): 474-479, doi: 10.1016/00029149(70)90016-0.

14. Pelech AN. Coronary Artery Fistula (2008). http://www.emedicine.com/ped/topic2505.html (Last accessed on 2008 Mar 21).

15. Podolec J, Wiewiórka $\measuredangle$, Siudak $Z$, et al. Presence and characteristics of coronary artery fistulas among patients undergoing coronary angiography. Kardiol Pol. 2019; 77(11): 1034-1039, doi: 10.33963/KP.14963, indexed in Pubmed: 31486416

16. Qureshi R, Kao L, Gupta RP. Coronary artery fistula with associated Takotsubo cardiomyopathy: a case report. J Med Case Rep. 2018; 12(1): 86, doi: 10.1186/s13256018-1567-5, indexed in Pubmed: 29602306.

17. Saboo SS, Juan YH, Khandelwal A, et al. MDCT of congenital coronary artery fistulas. AJR Am J Roentgenol. 2014; 203(3): W244-W252, doi: 10.2214/AJR.13.12026, indexed in Pubmed: 25148180.

18. Said SAM, Oortman RM, Hofstra JH, et al. Coronary artery-bronchial artery fistulas: report of two Dutch cases with a review of the literature. Neth Heart J. 2014; 22(4): 139-147, doi: 10.1007/s12471-014-0518-z, indexed in Pubmed: 24464641.

19. Sakakibara S, Yokoyama M, Takao A, et al. Coronary arteriovenous fistula. Am Heart J. 1966; 72(3): 307-314, doi: 10.1016/s0002-8703(66)80004-2.

20. Salah AM. Solitary coronary artery fistulas: a congenital anomaly in children and adults. A contemporary review. World J Cardiol. 1966; 2(1): 6-12.

21. Salah SA, Schiphorst RH, Derksen R, et al. Coronary-cameral fistulas in adults: Acquired types (second of two parts). World J Cardiol. 2013; 5(12): 484-494, doi: 10.4330/wjc. v5.i12.484, indexed in Pubmed: 24432186.

22. Schumacher G, Roithmaier A, Lorenz HP, et al. Congenital coronary artery fistula in infancy and childhood: diagnostic and therapeutic aspects. Thorac Cardiovasc Surg. 1997; 45(6): 287-294, doi: 10.1055/s-2007-1013751, indexed in Pubmed: 9477461.

23. Shi K, Gao HL, Yang ZG, et al. Preoperative evaluation of coronary artery fistula using dual-source computed tomography. Int J Cardiol. 2017; 228: 80-85, doi: 10.1016/j. ijcard.2016.11.169, indexed in Pubmed: 27863365.

24. Sun JP, Yang L, Zhao Z, et al. A rare right coronary artery-left ventricular fistula with giant coronary artery and aneurysm. Eur Heart J Cardiovasc Imaging. 2019; 20(5): 604, doi: 10.1093/ehjci/jey229, indexed in Pubmed: 30649361.

25. Uzu K, Otake H, Choi G, et al. Lumen boundaries extracted from coronary computed tomography angiography on computed fractional flow reserve (FFRCT): validation with optical coherence tomography. Eurolntervention. 2019; 14(15): e1609-e1618, doi: 10.4244/EIJ-D-17-01132, indexed in Pubmed: 29616627.

26. Villa AD, Sammut E, Nair A, et al. Coronary artery anomalies overview: The normal and the abnormal. World J Radiol. 2016; 8(6): 537-555, doi: 10.4329/wjr.v8.i6.537, indexed in Pubmed: 27358682.

27. Wen B, Yang J, Jiao Z, et al. Right coronary artery fistula misdiagnosed as right atrial cardiac myxoma: A case report. Oncol Lett. 2016; 11(6): 3715-3718, doi: 10.3892/ ol.2016.4457, indexed in Pubmed: 27284376.

28. Xu H, Zhu Y, Zhu X, et al. Anomalous coronary arteries: depiction at dual-source computed tomographic coronary angiography. J Thorac Cardiovasc Surg. 2012; 143(6): 1286-1291, doi: 10.1016/j.jtcvs.2011.11.025, indexed in Pubmed: 22154794.

29. Zhou K, Kong L, Wang Y, et al. Coronary artery fistula in adults: evaluation with dual-source $\mathrm{CT}$ coronary angiography. Br J Radiol. 2015; 88(1049): 20140754, doi: 10.1259/ bjr.20140754, indexed in Pubmed: 25784320. 